\title{
Poor access to primary care for Aboriginal patients in Canada: What are the barriers?
}

\author{
April Clyburne-Sherin \\ (University of Guelph) \\ News Reporter (HSI 2013-2014)
}

Gaps in health outcomes of Aboriginal people are recognized across Canada. ${ }^{1,2,3,4,5}$ In British Columbia, the Aboriginal population has 2 to 5 times the age-standardized mortality rate for medically treatable diseases compared to the nonAboriginal population. ${ }^{1,2}$ On a national level, Aboriginal people are 1.1 to 2.5 times as likely as non-Aboriginal people - with similar geographic or socioeconomic backgrounds - to be admitted to hospital for conditions that are preventable through primary care. ${ }^{6,7}$ These findings have prompted Dr. Marcia Anderson-DeCouteau, a Canadian physician and former president of the Indigenous Physicians Association of Canada, to assert that Canada needs "to examine the care of First Nations people in the health care system". ${ }^{8}$

Measuring access to primary care directly is difficult; thus, other healthcare indicators that may be correlated with primary care access are often used. Considering that primary care is correlated with lower admissions to hospital for preventable conditions and emergency department visits ${ }^{9}$, the increased mortality and admission rates in Aboriginal groups may reflect gaps in access to primary care..$^{1,2}$ Although both on-reserve and off-reserve Aboriginal patients have higher admission rates than non-Aboriginal patients, the odds of hospitalization are twice as high for Aboriginal patients living on-reserve compared to off-reserve. ${ }^{10}$ Comparing specialist referrals from primary care physicians is another way of measuring access to primary care. Aboriginal populations are 0.6 to 1.0 times less likely to receive appropriate referrals than nonAboriginal people with similar geographic or socioeconomic backgrounds. ${ }^{7}$ For example, Aboriginal populations are $43 \%$ less likely than non-Aboriginal populations with chronic kidney disease to visit a nephrologist. ${ }^{6}$

Barriers to primary care access for Aboriginal populations are complex, but can be categorized as patient-provider barriers, health clinic access barriers, and systemic barriers. ${ }^{3,11}$ Patient-provider barriers to primary care access include issues such as the communication and relationships between patients and physicians. ${ }^{4}$ Aboriginal patient interviews have outlined concerns that doctors may be prejudging and dismissing their health concerns during visits based on their Aboriginal status, economic standing, housing situation, or assumed substance use..$^{1,2}$ Dr. Anderson-DeCouteau believes that physician prejudice is commonly experienced by Aboriginal patients: "There are certain types of patients that it's okay to care less about... and certainly Aboriginal people are at the top of the list". ${ }^{8}$ Some patients have identified this concern of prejudice as a factor that has delayed or inhibited their seeking of health care. ${ }^{1,2}$ Doctor interviews on patientprovider factors are split between those who believe the communication and understanding between Aboriginal patients and their doctors needs to improve, and those who believe that Aboriginal patients need to take more personal responsibility for their health. ${ }^{11}$

To improve relationships between physicians and patients, educational interventions in medical school could allow future doctors to improve cultural competence, cultural sensitivity, doctor-patient partnerships, advocacy, and communication. ${ }^{4,11,12}$ Specifically, physicians can build culturally sensitive communication with patients by allowing patients to speak more, increasing the time for a consultation, and becoming more comfortable with silence. ${ }^{13}$

Clinic level barriers to primary care include understaffing and staff turnover. ${ }^{11}$ Doctor interviews have highlighted clinic barriers to primary care for Aboriginal patients such as deficient emergency and social service resources. ${ }^{1,2}$ Although these factors also impact non-Aboriginal patients, doctors specifically identified these factors as preventing the proper treatment of Aboriginal patients who may require additional referrals to primary care and social services. ${ }^{1,2}$ Solutions at a clinical level for improving access involve building the capacity, resources and time to appropriately refer Aboriginal patients entering the emergency department or walk-in clinics to the appropriate primary care service. Consistent referral to social workers, specialists, or addiction services would not only improve 
emergency department efficiency but ultimately help improve patient outcomes. ${ }^{1,2}$

The most complex barriers to primary care access are systemic factors, and most importantly the continuing impact of colonization. ${ }^{3}$ As Dr. Anderson-DeCouteau recalled, "In medical school... there is no historical context, no understanding of the impacts of colonization or residential schools, and how that might have impacted our current day health status or current day socio-economic circumstances". ${ }^{8} \mathrm{~A}$ postcolonial framework in healthcare research provides context to barriers related to race, class, and gender, and how personal and collective health care experiences shape current health care decisions. ${ }^{1,2,14}$ One example of a systemic access barrier stems from the trauma of the residential school system from 1876 -1996, where Aboriginal survivors were subjected to emotional, physical, or sexual abuse by people in positions of authority. ${ }^{1,2}$ Within this context, it is not surprising that Aboriginal patients who have experienced or were affected by this trauma are especially aware of power imbalances within the health care system, ${ }^{3}$ often resulting in feelings of anxiety during interactions with people in positions of authority such as doctors. ${ }^{1,2,3}$

System-level barriers to care require a critical understanding of the power dynamics entrenched in the health care system. ${ }^{3}$ Of the systemic changes that may equalize these dynamics, easing the navigation and permeability of health services may be of significant benefit to the health care experience of Aboriginal patients. ${ }^{3}$ Examples of these changes include community-entrenched health clinics, Aboriginal managerial and reception staff, as well as the incorporation of indigenous knowledge, accessible transportation, low cost services, flexible hours, and opendoor policies. ${ }^{3}$ As discussed, addressing these barriers will be the first step in improving primary care access for Aboriginal patients: "So often, these patients or their families get dismissed. Their voices aren't really listened to," Dr. Anderson-DeCouteau says. "There needs to be a voice for people who are too often rendered voiceless." ${ }^{8}$

\section{References}

1. Browne AJ, Smye VL, Rodney P, Tang SY, Mussell B, O'Neil J. Access to Primary Care From the Perspective of Aboriginal Patients at an Urban Emergency Department. Qual Health Res. 2011;21(3):333-348.

2. Browne AJ, Varcoe CM, Wong ST, Smye VL, Lavoie J, Littlejohn D, Tu D, Godwin O, Krause M, Khan KB, Fridkin A, Rodney P, O'Neil J, Lennox S. Closing the health equity gap: evidence-based strategies for primary health care organizations. International Journal for Equity in Health. 2012;11:59.

3. Peiris D, Brown A, Cass A. Addressing inequities in access to quality health care for indigenous people. Can Med Assoc J. 2008;179(10):985-986.

4. Towle A, Godolphin W, Alexander T. Doctor-patient communications in the aboriginal community: Towards the development of educational programs. Patient Educ Couns. 2006;62(3):340-346.

5. Wilson K, Cardwell N. Urban Aboriginal health. Examining inequalities between Aboriginal and non-Aboriginal populations in Canada. Canadian Geographer-Geographe Canadien. 2012;56(1):98-116.

6. Gao S, Manns BJ, Culleton BF, Tonelli M, Quan H, Crowshoe L, Ghali WA, Svenson LW, Ahmed S, Hemmelgarn BR, Alberta Kidney Dis Network. Access to health care among status Aboriginal people with chronic kidney disease. Can Med Assoc J. 2008;179(10):1007-1012.

7. Shan BR, Gunraj N, Hux JE. Markers of access to and quality of primary care for aboriginal people in Ontario, Canada. Am J Public Health. 2003;93(5):798-802.

8. Anderson-DeCouteau, Marcia. White Coat Black Art with Dr. Brian Goldman: Improving the Healthcare System with Dr. Marcia Anderson-DeCoteau (Extended Interview). CBC, October 7, 2013.

9. Campbell DJT, Ronksley PE, Hemmelgarn BR, Zhang J, Barnabe C, Tonelli M, Manns B. Association of enrolment in primary care networks with diabetes care and outcomes among First Nations and low-income Albertans. Open medicine : a peer-reviewed, independent, open-access journal. 2012;6(4):e155-65.

10. Morrison L, Buckeridge DL, Xiao Y, Moghadas SM. The impact of geographical location of residence on disease outcomes among Canadian First Nations populations during the 2009 influenza A(H1N1) pandemic. Health \& Place. 2014;26:53-59.

11. Bhattacharyya OK, Estey EA, Rasooly IR, Harris S, Zwarenstein M, Barnsley J. Providers' perceptions of barriers to the management of type 2 diabetes in remote Aboriginal settings. Int J Circumpolar Health. 2011;70(5):552-563.

12. Buxton JA, Ouellette V, Brazier A, Whiteside C, Mathias R, Dawar M, Mulkins $A$. Bridging the gap in population health for rural and Aboriginal communities: a needs assessment of public health training for rural primary care physicians. Canadian journal of rural medicine : the official journal of the Society of Rural Physicians of Canada = Journal canadien de la medecine rurale : le journal officiel de la Societe de medecine rurale du Canada. 2007;12(2):81-8.

13. Kelly L, Brown JB. Listening to Native patients - Changes in physicians' understanding and behaviour. Canadian Family Physician. 2002;48:16451652.

14. Van Herk KA, Smith D, Gold ST. Safe care spaces and places: Exploring urban Aboriginal families' access to preventive care. Health Place. 2012;18(3):649656.

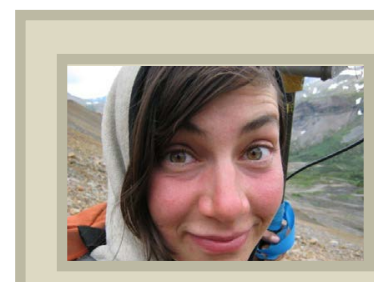

\section{April Clyburne-Sherin}

April Clyburne-Sherin is an MSc Candidate in Epidemiology in the Department of Population Medicine at the University of Guelph. With a background in ecology, April is interested in the relationships between ecosystems and human health, with a particular interest in Northern and Aboriginal health. April's graduate research explores spatial and statistical epidemiological methods using historical data. 